\title{
Teachers' and Students' Self-Efficacy Belief and Attitude Towards Hard-CLIL in Ethiopian Vocational Polytechnic Colleges
}

\author{
Solomon Kidane Girmay \\ Department of English Language and Literature, Bahir Dar University, Bahir Dar, Ethiopia
}

Email address:

solomonhiyab@gmail.com

To cite this article:

Solomon Kidane Girmay. Teachers' and Students' Self-Efficacy Belief and Attitude Towards Hard-CLIL in Ethiopian Vocational Polytechnic Colleges. English Language, Literature \& Culture. Vol. 3, No. 3, 2018, pp. 37-41. doi: 10.11648/j.ellc.20180303.11

Received: December 11, 2018; Accepted: January 14, 2019; Published: February 31, 2019

\begin{abstract}
Foreign language education is a complex psycho-pedagogical phenomenon which requires apparent understanding of different factors which influence the academic achievement in school environment. Self-efficacy belief and attitude are key affective factors to teachers' and learners' accomplishment in foreign language teaching. This research paper examines vocational teachers' and students' self-efficacy belief and attitude towards content and language integrated learning (CLIL) in Bahir Dar Vocational Polytechnic College. For this purpose 100 students and 25 teachers were selected using availability sampling. Questionnaire was used for data gathering, and the data gathered through questionnaire was analyzed using T-test. Findings revealed that both teachers' and students' self-efficacy belief was very low and their attitude was also significantly negative. Based on the results of this study, conclusions were made and recommendations were forwarded.
\end{abstract}

Keywords: Affective Factors, Attitude, Content and Language Integrated Learning (CLIL), Polytechnic Vocational College, Self-Efficacy Belief

\section{Introduction}

The establishment and development of TVET education in Ethiopia aims to train the middle level work force which is necessary for the national economic growth and development, and to equip students with appropriate professional knowledge and specialized skills for the job market. Therefore, TVET intends to produce professionals who can copy new and selected technologies and transfer required technologies to the relevant industry in order to increase productivity and the competitiveness of the sector on the bases of international standards, and by doing so, to contribute to poverty reduction and sustainable development (Federal Ministry of Education, 2010) [2]. In other words, the current TVET system is career-oriented, with the aim of training manpower to meet the demands of national economic growth, industrial changes, social needs, and technological advancement.

Furthermore, it is required to refer to international best practice and use it as a basis for occupational standard and curriculum development in order to adapt and transfer the technologies (Ministry of Education, 2008) [1]. As a result, with the trend towards internationalism, workplaces and industries require human resources to be proficient in an international language (e.g. English). It is believed that people who are fluent in English (i.e., listening, reading, writing, and speaking) have better opportunities in the job market; therefore, EFL becomes a core required competence in the technical and vocational education as it is in other education systems.

Currently, language is not given as a discrete subject in TVET colleges throughout the country. It is believed that language is being taught being integrated with main subject courses. In other words, the main course teachers are responsible to enhance the language proficiency of their students in TVET program. Scholars also claim that the implementation of content and language integrated learning (CLIL) attributes to significant changes in the way in which teaching is planned, sequenced and carried out. "The adoption of a new curriculum, which integrates linguistic and nonlinguistic material, as well as the linguistic and methodological needs that come with the introduction of this 
type of teaching, have generated feelings of concern and uncertainty" (Vazquez and Rubio, 2010: 45) [3].

There is a clear need for pedagogical practitioners to be aware of and understand need of English language competency so as to meet the aim and purpose of the training in TVET. Moreover, Hua (2012) [4] stated that the worldwide spread of English language has led to a diversity of English language needs. This is reflected in the development of English for Specific Purposes (ESP). In the vocational education system, vocational-oriented courses are offered to prepare students for their future occupation. Specialized curricula are devised to meet the requirements of different disciplines. This is also true in the case of English language education in Ethiopian technical and vocational schools (TVSs). Integrated curriculums are introduced to TVET programs; as a result, language, mathematics and entrepreneurship courses are offered integrated with major courses.

The integration of language in a content or major course is named as CLIL (content and language integrated learning) and first introduced in Europe by David Marsh in 1994. In an attempt for better understanding of Content and Language Integration for foreign language learning, different studies came up with different models and continuums. Scholars described CLIL programs along a continuum that goes from a focus on foreign language learning, at one end, to a greater interest in curricular instruction through a foreign language, at the other end. The ranges of the continuum are named differently as: content-driven vs. language-driven (Met, 1999) [5], content-oriented vs. language-oriented Verdugo, as cited in Ioannou-Georgiou and Pavlou, 2010) [6], hard CLIL vs. soft CLIL (Bentley, 2010) [7], strong vs. weak versions of CLIL (Brinton, Snow and Wesche, 2003) [8], subject-led vs. language-led (Clegg, 2003) [9] based on the context that language is used to teach curricular subjects and the topics or contents from the curricular subjects are used to teach language, respectively.

In the context that this study is conducted, a content-driven CLIL (hard-CLIL) is the continuum which is being implemented. Glusac (2012) [10] defined a hard-CLIL as a pedagogical approach in which additional language can be a medium of instruction in teaching of other school subjects. Teachers are expected to teach language beside the content though the main objective is the acquisition of the content. Teachers are also trained to teach content. This means that the CLIL teachers do not have taken pedagogical trainings to teach language (FL) along with their course.

On the other hand, the academic performance of learners is not good. Learners enroll in a technical and vocational program are those who do not perform well academically and fell to join higher education. According to Desta (2001) [11], "In Africa the TVET programs were considered [as] a career path for the less academically advantaged. Some African governments keep dropouts or 'lockouts', students who are unable to move up the educational ladder, not because of poor grades but because of lack of places at the higher level." On the other hand, better performing learners do not choose technical and vocational schools, but instead choose general universities to continue their higher education. According to the researcher's experience of teaching English as a subject in the vocational education system, students in this program possess low confidence and motivation in learning. Thus, this study tends to describe TVET teachers' and students' selfefficacy belief and attitude towards CLIL.

Self-efficacy belief and attitude are two of the main effective predictors of educational outcomes. Self-efficacy belief refers to people's judgment of their own ability to accomplish a sort of tasks effectively. As Bandura, in Hsieh (2008: 79) [12], defined y "Self-efficacy refers to people's judgment of their capabilities to complete a task successfully." Whereas, an attitude is a view that people have towards an entity in a form of favor or disfavor towards that entity.

Scholars stated that in Education, self-efficacy and attitude are key causative factors to teachers' and learners' accomplishment. Self-efficacy influences the choices teachers and learners make and the courses of action they pursue (Pajares, 2002) [13]. Similarly, attitude is also vital, as it influences teachers' motivation to work with their students, which can, in turn, transform into higher student motivation and performance. For instance, as Sharma and Nasa (2014) [14] state, self-efficacy belief is the self concept or the personal understanding of one's own ability to perform a certain task successfully. It has a powerful influence on the choice of activity one make, the kind of effort one spends, and the level of effort maintained in the face of difficulty.

Various studies have been conducted on the role of attitudes in first language, second language, (modern) foreign language and bi- lingual teaching and learning contexts. However, much is not done on the self-efficacy belief and attitude related to CLIL (content-driven in particular) in the Ethiopian context.

\section{Methods}

\subsection{Design of the Study}

This research followed a quantitative research approach and a descriptive cross-sectional survey design. In order to gather information related to the research questions, questionnaires on self-efficacy beliefs and attitudes were administered.

\subsection{Participants}

A total of one hundred Level III and IV students and twenty five teachers of Bahir Dar Technical and Vocational Polytechnic College participated in this study. All the student participants enrolled in the regular program at the time of data collection which is 2010 E.C/2018 G.C. On the other hand, all twenty five teacher participants were major course trainers, and $\mathrm{B}$ level teachers (have first degree) except two who were $C$ level teachers $(10+3$ or level 4 graduates). The researcher used non-probability sampling technique (i.e., available sampling technique). According to Creswell (2012: 
145), "In non-probability sampling, the researcher selects individuals because they are available, convenient, and represent some characteristic the investigator seeks to study."

\subsection{Instruments}

The researcher used closed and structured questionnaires to gather data about teachers' and students' self-efficacy belief and attitude towards CLIL. Both the teachers' and students' self efficacy belief questionnaires had 12 items while 11 items were included in the questionnaires of attitude towards CLIL. The items of both the trainers' and trainees' questionnaires are identical. The items are scored on a 1 to 5 point Likert scale (from strongly disagree to strongly agree).

\subsection{Data Analysis}

The data is analyzed quantitatively, and the Statistical Package for the Social Sciences (SPSS), Version 20.0 was used for analysis. 95 student respondents' and 24 teacher respondents' responses were used for data analysis purpose, for the researchers discarded the rest due to response errors. Since the main purpose of this study was to describe the selfefficacy belief and attitude of TVET teachers and learners towards CLIL, one sample t-test is employed to calculate the mean value.

\section{Results and Discussions}

Theoretically, it is assumed that self-efficacy belief and attitude are the determinants of performance, success and accomplishments in education. Having good self efficacy belief and a positive attitude towards an activity leads to effectiveness. In line to these, the findings in this study describe the existing self-efficacy belief and attitude of TVET teachers and learners. The table below shows the statistical value of the responses of the respondents.

Table 1. Learners' Self-efficacy Belief (LSEB).

\begin{tabular}{lllllllll}
\hline & $\mathbf{N}$ & Mean & $\mathbf{t}$ & \multirow{2}{*}{$\begin{array}{l}\text { Sig. (2 } \\
\text { tailed) }\end{array}$} & $\begin{array}{l}\text { Mean } \\
\text { difference }\end{array}$ & \multicolumn{2}{l}{$\begin{array}{l}\text { 95\% Confidence interval of the difference } \\
\text { Lower }\end{array}$} \\
\hline LSEB & 95 & 34.12 & -4.77 & 94 & .000 & -1.88 & -2.67 \\
\hline
\end{tabular}

Table 1 displays the statistical mean value of the students self efficacy belief. The mean value of the learners' response for the self-efficacy belief items is 34.12 , the expected mean value (36), and the $t$ value $=-4.77$, while the $d f$ is 94 , the $p$ value is 0.000 . The mean difference between the expected mean and the calculated mean value of the respondents' is 1.88. Therefore, since the $p<0.001$ and it is below 0.05 , the calculated mean value is found significantly lower than the expected mean value. In other words, trainees' self-efficacy belief is found to be negative. However, in theory, it is noted that learners who attain high level of self-efficacy are more self-confident and have more positive attitude towards their education (Sharma and Nasa, 2014) [14]. Therefore, there is a possibility that students without a high level of self-efficacy belief cannot be successful in their education. To strengthen this, Pajeres (2002) [13] also noted that self-efficacy is a key psychological variable (affective factor) to learners' success, since self-efficacy determines the choices learners make and the courses of action they pursue.

Table 2. Students' Attitude (SA).

\begin{tabular}{|c|c|c|c|c|c|c|c|c|}
\hline \multirow[b]{3}{*}{ SA } & \multirow{3}{*}{$\mathbf{N}$} & \multirow{2}{*}{ Mean } & \multirow{2}{*}{$t$} & \multirow{2}{*}{$d f$} & \multirow{2}{*}{ Sig. (2 tailed) } & \multirow{2}{*}{ Mean difference } & \multicolumn{2}{|c|}{$95 \%$ Confidence interval of the difference } \\
\hline & & & & & & & Lower & Upper \\
\hline & & 31.96 & -2.28 & 94 & .025 & -1.04 & -1.95 & -.13 \\
\hline
\end{tabular}

The above table portrays the one-sample t-test statistical mean value of learners' response for the attitude items. The learners' response mean (31.96) is less than the expected mean value (33), and the $t$ value $=-2.28, d f(94)$. The mean difference is -1.04 . The t-test also indicates a slightly difference between the expected mean and the calculated mean at $\mathrm{p}<0.025$. In other words, since the $\mathrm{p}$ value is lower than 0.05 , it signifies that the mean value is significantly lower than the expected mean value. This shows that the learners have a negative attitude towards CLIL. The result, however, contradicts with the literature and research findings. For instance, Marsh (2000: 10) [16] stated that the main goal of CLIL is to create a 'can do' attitude towards language learning. Furthermore, Lasagabaster and Sierra (2009: 4) [17] conducted a research on "Language Attitudes in CLIL and Traditional EFL Classes" and found that CLIL programs help to foster positive attitudes towards language learning in general. Similarly, Merisuo-Storm as cited in Vazquez and Ellison (2013) [18] stated that attaining significantly more positive attitudes towards language learning has been demonstrated as one of the social benefits of students in CLIL classes. However, as stated earlier the calculated mean score (31.96) which is lower than the expected mean (33) refers that participant students have a significantly negative attitude towards CLIL.

Table 3. Teachers'Self-efficacy Belief (TSEB).

\begin{tabular}{|c|c|c|c|c|c|c|c|c|}
\hline & \multirow{2}{*}{$\mathbf{N}$} & \multirow{2}{*}{ Mean } & \multirow{2}{*}{$t$} & \multirow{2}{*}{$d f$} & \multirow{2}{*}{ Sig. (2 tailed) } & \multirow{2}{*}{ Mean difference } & \multicolumn{2}{|c|}{$95 \%$ Confidence interval of the difference } \\
\hline & & & & & & & Lower & Upper \\
\hline TSEB & 24 & 32.25 & -3.35 & 23 & .003 & -3.75 & -6.06 & -1.44 \\
\hline
\end{tabular}


According to the above table, the expected mean value for the self-efficacy belief items of the teacher respondents is 36 ; however, the teachers' response mean is found 32.25 and it is significantly lower than the expected mean (36), and $t$ value $=$ $3.35, d f 23 ; p=0.003$. Again these figures reveal that the teacher respondents are not self-efficacious. Furthermore, the $p$ value is less than 0.05 and it shows that the mean difference which is 3.75 is significant. In other words, the numbers in the above data signify that the self-efficacy belief of the teacher respondents towards CLIL is very low. Nevertheless, according to Vázquez and Rubio (2010) [3] enhancing self-efficacy belief is one of the dimensions that are normally considered as the main objectives of CLIL. Scholars argued that teachers' self-efficacy belief affects their work and has a direct relation with their learners' motivation and achievement. Teachers' low level of self-efficacy belief affects their practice and their learners' motivation and achievement negatively (Mojavezi and Tamiz, 2012) [19]. They also explicitly stated that teachers' self-efficacy belief positively affects students' achievement. Similarly, Chacon (2005: 257) [20] argued that "Teachers' sense of efficacy has been shown to influence teachers' actions and student outcomes."

Table 4. Teachers'Attitude (TA).

\begin{tabular}{|c|c|c|c|c|c|c|c|c|}
\hline & \multirow{2}{*}{$\mathbf{N}$} & \multirow{2}{*}{ Mean } & \multirow{2}{*}{$t$} & \multirow{2}{*}{$d f$} & \multirow{2}{*}{ Sig. (2 tailed) } & \multirow{2}{*}{ Mean difference } & \multicolumn{2}{|c|}{$95 \%$ Confidence interval of the difference } \\
\hline & & & & & & & Lower & Upper \\
\hline TA & 24 & 32.50 & -.50 & 23 & .621 & -.50 & -2.56 & 1.56 \\
\hline
\end{tabular}

Table 4 above shows that the teachers' response mean value for the attitude questionnaire is 32.50 while the expected mean value is 33 , and the $t$ value $=-0.50, d f(23), p$ $<0.621$. Unlike the other tables, the $p$ - value on the above table is a somewhat higher than 0.05 . It indicates that, even if the expected mean value (33) is higher than the calculated mean value (32.5), the mean difference $(\mathrm{MD}=-0.5)$ is not statistically significant. In general, this table describes that teacher respondents have a negative attitude towards CLIL. The implication behind this result is that content teachers do not have a positive attitude of teaching language integrating it with main courses. Unlike this study, Vázquez and Rubio (2010) [3] in their research on 'Teachers' Concerns and Uncertainties about the introduction of CLIL Programs' found that teachers have showed a very positive attitude towards this challenge and have proved an enormous dose of effort to make it happen. A study on integrating CLIL at the tertiary level by Dafouz et al as cited in McDougald (2015) [21] also revealed a positive attitude towards CLIL implementation amongst teachers and students.

\section{Conclusions}

According to Bandura, in Chacon (2005) [21], teachers' self efficacy beliefs in their pedagogical effectiveness affect the kind of atmosphere they create to orchestrate learning. However, based on the results of this study, it is concluded that both TVET teachers and students have very low selfefficacy beliefs towards hard CLIL.

Similarly, attitude of teachers' and learners' was also found negative. Therefore, this researcher concludes that Polytechnic TEVET College students and teachers have negative attitude towards hard CLIL. Negative attitude hinders motivation or desire and this can consequently impede second language progress.

In general, the results of this study clearly contradict with the goals of CLIL. Therefore, the researcher of this study concludes that CLIL is not being implemented appropriately in Bahr Dar Polytechnic TVET College; as a result, hard CLIL is not effective enough to enhance the self-efficacy belief and attitude of learners and teachers. This leads the researcher to wonder whether the use of another form of Content and Language Integrated Learning (i.e., the soft CLIL) approach could possibly create and enhance such affective variables.

\section{References}

[1] Ministry of Education (2008) National Technical \& Vocational Education $\&$ Training (TVET) Strategy $\left(2^{\text {nd }} e d\right)$.

[2] Federal Ministry of Education (2010) Education Sector Development Program IV. Program Action Plan, 2010/2011 2014/2015, Addis Ababa.

[3] Vazquez, V. P. and Rubio, F. (2010). Teachers' Concerns and Uncertainties about the Introduction of CLIL Programs. [Porta Linguarum], 14, pp.45-58. Received: 6 June 2009 / Accepted: 20 November 2009, ISSN: 1697-7467.

[4] Hua, T. L. (2012). English Language Education in Vocational High Schools in Taiwan: A Study from an English for Specific Purposes Perspective. Athens: ATINER'S Conference Paper Series, No: EDU2012-0118.

[5] Met, M. (1999, January). Content-based instruction: defining terms, making decisions. [NFLC Reports]. Washington, DC: The National Foreign Language Center.

[6] Ioannou-Georgiouu, S. \& Pavlou, P. (Eds.) (2010). Guidelines for CLIL implementation in primary and pre-primary education. Comenius Socrates Project.

[7] Bentley, K. (2010). The TKT course: CLIL module. Cambridge: Cambridge University Press.

[8] Brinton, D. M., Snow, M. A. \& Wesche, M. (2003). Contentbased second language instruction: Michigan classics ( $\left.2^{\text {nd }} e d.\right)$. New York, NY: Newbury House.

[9] Clegg, J. (2003). The Lingue E Scienze Project: Some outcomes. [The Language and Science Project: Some outcomes.] In T. Boella \& T. Barbero, L'Uso veicolare della lingua straniera in apprendimenti non linguistici.[The use of a foreign language as medium in non-language learning.] Centro Diffisione Comunitaire Quaderni 6. Ufficio Scolastico Regionale per Piemonte, Torino. 
[10] Glusac, T. (2012). CLIL and one-to-one classes. In R. Popovic and V. Savic (Eds.), Content and language integrat learning (CLIL) in teaching English to young learners. Conference Proceedings No. 11; pp. 63-73.

[11] Desta, A., Ph.D. (n.d.) The Integration of Technical and Vocational Education and Training with Sustainable Development Education: A Review of African Case Studies.

[12] Hsieh, P. (2008) "Why are College Foreign Language Students' Self-efficacy, Attitude, and Motivation so Different?" International Education, Volume 38(1), pp. 76-94 Retrieved from: http://trace.tennessee.edu/internationaleducation/vol38/iss1/11

[13] Pajares, F. (2002). Overview of social cognitive theory and of self-efficacy. Retrieved at http://www.emory.edu/EDUCATION/mfp/eff.html.

[14] Sharma, H. L. and Nasa, G. (2014). Academic self-efficacy: A reliable predictor of educational performances. Britis Journal of Education, Vol.2, No.3, pp. 57-64, July 2014. Published by European Centre for Research Training and Development UK (www.ea-journals.org).

[15] Creswell, J. W. (2012). Educational Research: Planning, Conducting, and Evaluating Quantitative and Qualitative Research. Boston: Pearson Education, Inc.
[16] Marsh, D. (2000). Using Languages to Learn and Learning to Use Languages. Finland: University of Jyvaskyla.

[17] Lasagabaster, D. and Sierra, J. M. (2009). Language Attitudes in CLIL and Traditional EFL Classes. International CLIL Research Journal, 1 (2), pp. 4-17. Retrieved at: http://www.icrj.eu/12/article1.html.

[18] Vazquez, V. P. and Ellison, M. (2013). Examining teacher roles and competences in Content and Language Integrated Learning (CLIL). [Lingvarvmarena], 4, pp. $65-78$.

[19] Mojavezi, A. and Tamiz, M. P. (2012) The Impact of Teacher Self-efficacy on the Students' Motivation and Achievement. Theory and Practice in Language Studies, Vol. 2(3), pp. 483491, Finland: Academy Publisher, doi:10.4304/tpls.2.3.483491.

[20] Chacon, C. T. (2005) Teachers' perceived efficacy among English as a foreign language teachers in middle schools in Venezuela. Teaching and Teacher Education 21, pp. 257-272; Elsevier Ltd.

[21] McDougald, J. (2015). Teachers' attitudes, perceptions and experiences in CLIL: A look at content and language. Colomb. Appl. Linguist. J., 17(1), pp. 25-41. ISSN 0123-4641. 